\title{
Effectiveness of Short-Term Heart Rate Variability Biofeedback Training and the Risk of Internet Addiction in Adolescents 15-16 Years of Age
}

\author{
Liliya V. Poskotinova, PhD, ScD*; Olga V. Krivonogova, PhD; Oleg S. Zaborsky \\ N. Laverov Federal Center for Integrated Arctic Research \\ Arkhangelsk, the Russian Federation
}

\begin{abstract}
Background: Adolescents with an Internet overuse problem and risk of Internet addiction (IA) have a disturbed autonomic nervous system balance. The aim of the study was to determine the effectiveness of short-term heart rate variability biofeedback (HRV-BF) training to increase the total power (TP) of HRV spectrum in adolescents 15-16 years of age with different risks of IA development.

Methods and Results: The study involved 20 healthy youths (15-16 years of age) of Arkhangelsk secondary school. The survey was conducted using the Chen Internet Addiction Scale (CIAS) in the Russian version of Malygin et al.(2011). SBP (systolic blood pressure), DBP (diastolic blood pressure) and HRV indicators (HR [heart rate], TP of the HRV spectrum, and SI [Stress Index]) were recorded in relaxation ( $3 \mathrm{~min}$ ) and during the HRV-BF training session ( $3 \mathrm{~min}$ ). According to the CIAS score, 2 groups were identified: Group $1(\mathrm{n}=9)$ with minimal IA risk (CIAS score $<47)$ and Group $2(\mathrm{n}=11)$ with significant IA risk (CIAS score $\geq 47$ points). Group 1, after HRV-BF training, showed a significant increase in TP compared to the initial value, on average by 2.3 times $(P=0.036)$. At the same time, SI decreased significantly $(P=0.025)$. In Group 2 , after HRV-BF training we did not find significant change in TP and SI, compared to the initial data. Moreover, HR became statistically higher $(P=0.021)$. TP level after HRV-BF training in Group I was significantly higher than in Group $2(P=0.043)$. SBP and DBP did not statistically change during the training in both groups. Correlation analysis performed on the total sample $(\mathrm{n}=20)$ revealed a significant negative correlation between high TP levels during HRV-BF training and low CIAS scores on the Wit-scale $\left(\mathrm{r}_{\mathrm{s}}=-0.46, P=0.048\right)$.

Conclusion: A significant risk of IA developing in puberty may be accompanied by a decrease in the autonomic nervous reactivity during the HRV-BF session. The greatest influence on reduction of HRV-BF efficiency during short-term training has withdrawal symptoms associated with excessive Internet use. (International Journal of Biomedicine. 2020;10(2):153-156.)
\end{abstract}

Key Words: Internet addiction • adolescents • heart rate variability biofeedback

\section{Abbreviations}

HR, heart rate; SBP, systolic blood pressure; DBP, diastolic blood pressure; HRV, heart rate variability; IA, Internet addiction; TP, total power; SI, Stress Index; BMI, body mass index.

\section{Introduction}

In the adolescent period, the autonomic regulation of cardiac activity remains imperfect due to an unstable sympathovagal balance. At the same time, young people become highly involved in Internet communication due to the educational purposes and because of the high need for

*Corresponding author: Liliya V. Poskotinova, PhD, ScD. Department of Biorhythmology of $N$. Laverov Federal Center for Integrated Arctic Research, Arkhangelsk, Russia. E-mail: liliya200572@mail.ru positioning ourselves in the media space. Because of this involvement, adolescents may develop signs of Internet addiction, exhibiting also the symptoms of deteriorating health. Cerniglia et al. identify IA as a non-chemical behavioral addiction that includes the interaction of a person with a machine as an "instrumental" form of social interaction (i.e. a form of addiction mediated by machines). ${ }^{(1)}$ Chen and coauthors proposed psycho-diagnostic tools that can determine the level of risk of developing IA, including in adolescents. ${ }^{(2,3)}$ There is evidence of reduced background overall HRV in individuals with problematic Internet use, and in individuals with Internet gaming addiction, ${ }^{(4)}$ which indicates a reduced 
autonomic flexibility.(5) HRV-BF training helps to optimize the mechanisms of baroreflex, an increase in TP of HRV and vagal effects on HR. ${ }^{(6)}$ Short-term HRV-BF training can be considered as a kind of cognitive test, when in a short period of time people are able to implement a strategy to purposefully change their visceral functions. ${ }^{(7)}$ The issue of the effectiveness of HRV-BF training in individuals with IA, or the risk of its development, remains open.

The aim of the study was to determine the effectiveness of short-term heart rate variability biofeedback (HRV-BF) training to increase the total power (TP) of HRV spectrum in adolescents 15-16 years of age with different risks of IA development.

\section{Materials and Methods}

The study involved 20 healthy youths (15-16 years of age) of Arkhangelsk secondary school. The study was conducted in January 2020. The study was approved by the Ethics Committee of the N. Laverov Federal Center for Integrated Arctic Research, RAS (Protocol №3 dated 12.02.2020). Written informed consent was obtained from all participants.

Affiliation to healthy persons was established according to the rules formulated by Order No. $514 \mathrm{n}$ of the MHRF dated 08.10.17. ${ }^{(8)}$ Height and BMI were between the third and the 97th percentile, according to growth charts for height-forage (for boys) and BMI-for-age (for boys). ${ }^{(9)}$ The survey was conducted using the Chen Internet Addiction Scale (CIAS) ${ }^{(2)}$ in the Russian version of Malygin et al. ${ }^{(10)}$ The CIAS is a selfreport measurement consisting of 26 items on a 4-point Likert scale-from 1 point (does not match my experience) up to 4 points (definitely matches my experience). Thus, the minimum CIAS score was 26 points, and the maximum was 104 points. Respondents with a CIAS score above 64 points were considered persons with symptoms of Internet-dependent behavior. ${ }^{(10,11)} \mathrm{A}$ score of 43 to 64 points was associated with a risk of developing Internet-dependent behavior, and less than 43 points indicated a minimal risk of such behavior. ${ }^{(10)}$ The total CIAS score was determined, as well as scores for Compulsive Use (Com), Withdrawal Symptoms (Wit), Tolerance (Tol), Interpersonal and Health-Related Problems (IH), and Time Management Problems (TM). The integral indicators reflecting the core symptoms of Internet overuse (IA-Sym $=\mathrm{Com}+\mathrm{Wit}+\mathrm{Tol})$ and problems associated with IA (IA- $\mathrm{RP}=\mathrm{IH}+\mathrm{TM}$ ) were also highlighted.

HRV indicators were recorded in the sitting position using the Ramena Varicard device (Russia). We determined HR (bpm), TP of the HRV spectrum $\left(\mathrm{ms}^{2}\right)$, and Stress Index (SI) (units), reflecting the level of sympathetic effects on the heart rhythm. SI was calculated by the formula $[\mathrm{SI}=\mathrm{Amo} 50 / 2 \times \mathrm{VAR} \times \mathrm{Mo}$, where $\mathrm{Mo}(\mathrm{MS})$ is the cardiointerval value dividing the cardiointerval-gram series in half, VAR - variation range between the minimum and maximum values in the cardio-interval-gram series, and Amo50,\% - amplitude of mode - number of R-R intervals]. HRV indicators were recorded in relaxation (3 $\mathrm{min})$ and during the HRV-BF training session (3 min), as well as SBP and DBP using an A\&D monitor (Japan). All participants had a 3-minute preliminary training. During HRV-BF training, the participant had to maintain a state of calmness and muscle relaxation, and breathe with a deep calm inhalation and a smooth, slow exhalation. The subject performed visual control of TP on a computer monitor, which should have increased with effective HRV-BF training. ${ }^{(12)}$

Statistical analysis was performed using the statistical software «Statistica». (v. 13.0, StatSoft, USA). Median values are presented with interquartile (IQ) ranges (IQR; 25th to 75th percentiles). The Mann-Whitney test was used to compare median values. The frequencies of categorical variables were compared using Pearson $\chi^{2}$. The Spearman correlation coefficient $\left(\mathrm{r}_{\mathrm{s}}\right)$ was used to assess the relationship between variables. A probability value of $P<0.05$ was considered statistically significant.

\section{Results}

It was found that only 2 people had a stable pattern of Internet-dependent behavior (CIAS score $>64$ points). In the total sample, the median CIAS score was 47 points with a range of Min-Max of 32-72 points (Table 1). According to the CIAS score, 2 groups were identified: Group $1(n=9)$ with minimal IA risk (CIAS score $<47)$ and Group $2(\mathrm{n}=11)$ with significant IA risk (CIAS score $\geq 47$ points). Group 2 had a significantly higher score on all CIAS scales, excluding Com.

\section{Table 1.}

CIAS score in the participants of both groups

\begin{tabular}{|l|c|c|c|c|c|}
\hline \multirow{2}{*}{ CIAS scales } & \multirow{2}{*}{$\begin{array}{c}\text { Me } \\
(\mathrm{n}=20)\end{array}$} & $\begin{array}{c}\text { Min-Max } \\
(\mathrm{n}=20)\end{array}$ & Group 1 & Group 2 & \multirow{2}{*}{$P$} \\
\cline { 4 - 5 } & & & $\mathrm{Me}\left(\mathrm{P}_{25} ; \mathrm{P}_{75}\right)$ & $\mathrm{Me}\left(\mathrm{P}_{25} ; \mathrm{P}_{75}\right)$ & \\
\hline CIAS score & 47 & $32-72$ & $39(35.5 ; 43.5)$ & $51(48 ; 57)$ & $<0.001$ \\
\hline IA-Sym & 27 & $19-39$ & $22(20 ; 26.5)$ & $28(27 ; 33)$ & 0.004 \\
\hline IA-RP & 20 & $13-33$ & $16.5(14 ; 18)$ & $24(20 ; 24)$ & $<0.001$ \\
\hline Com & 10 & $5-14$ & $8.5(7.5 ; 9.5)$ & $10(8 ; 13)$ & 0.104 \\
\hline Wit & 9 & $6-15$ & $8(7 ; 10)$ & $11(9 ; 11)$ & 0.015 \\
\hline Tol & 7 & $5-14$ & $6(5.5 ; 6.5)$ & $9(7 ; 10)$ & 0.013 \\
\hline IH & 11 & $7-16$ & $9(8 ; 11)$ & $13(11 ; 15)$ & 0.012 \\
\hline TM & 8 & $5-17$ & $6.5(6 ; 8)$ & $10(8 ; 13)$ & 0.003 \\
\hline
\end{tabular}

Initial values of HRV and blood pressure in the participants of both groups were statistically identical. Group 1, after HRV-BF training, showed a significant increase in TP compared to the initial value, on average by 2.3 times $(P=0.036)$ (Table 2). At the same time, SI decreased significantly $(P=0.025)$. Such results indicate that short-term HRV-BF training is effective, resulting in an increase in vagal influences and a decrease in sympathetic activity in relation to the autonomic regulation of heart rhythm.

In Group 2, after HRV-BF training we did not find significant change in TP and SI, compared to the initial data, which indicates the level of sympathetic activity was preserved, despite attempts by participants to find the optimal respiratory 
rate in order to increase the control indicator. Moreover, HR became statistically higher $(P=0.021)$. SBP and DBP did not statistically change during the training in both groups.

Table 2.

Cardiovascular parameters after HRV-BD training, $M e\left(P_{25} ; P_{75}\right)$

\begin{tabular}{|l|c|c|c|}
\hline \multicolumn{1}{|c|}{ Parameter } & Baseline & After HRV-BF training & P \\
\hline \multicolumn{4}{|c|}{ Group 1 (CIAS $<47)$} \\
\hline SBP, mmHg & $115(105 ; 119)$ & $118.5(117 ; 120.5)$ & 0.051 \\
\hline DBP, mmHg & $71(66 ; 74)$ & $71.5(66.5 ; 76.5)$ & 0.612 \\
\hline HR, bpm & $76(60 ; 91)$ & $78.5(67.5 ; 90)$ & 0.500 \\
\hline TPx1000, ms ${ }^{2}$ & $2.88(1.99 ; 6.74)$ & $6.55(4.04 ; 10.29)^{*}$ & 0.036 \\
\hline SI. units & $84.5(38 ; 237)$ & $36.5(31 ; 141)$ & 0.025 \\
\hline \multicolumn{4}{|c|}{ Group 2 (CIAS $\geq 47)$} \\
\hline SBP, mmHg & $116(113 ; 128)$ & $114.5(113 ; 123)$ & 0.374 \\
\hline DBP,mmHg & $69(63 ; 76)$ & $71.5(67 ; 76)$ & 0.386 \\
\hline HR, bpm & $75(70 ; 83)$ & $79.5(75 ; 81)$ & 0.021 \\
\hline TPx1000, ms ${ }^{2}$ & $3.03(2.52 ; 4.65)$ & $2.98(2.45 ; 3.36)^{*}$ & 0.213 \\
\hline SI, units & $92.5(69 ; 116)$ & $98.5(57 ; 143)$ & 0.423 \\
\hline
\end{tabular}

* - $P=0.043$ between Groups 1 and 2 groups after HRV-BF training

Correlation analysis performed on the total sample $(\mathrm{n}=20)$ revealed a significant negative correlation between high TP levels during HRV-BF training and low CIAS scores on the Wit-scale $\left(\mathrm{r}_{\mathrm{S}}=-0.46, P=0.048\right)$. After the exclusion of one person with a high TP $\left(>11,000 \mathrm{~ms}^{2}\right)$, this correlation became more pronounced $(\mathrm{r}=-0.68, P=0.003)$. Thus, a significant risk of IA developing in puberty may be accompanied by a decrease in the autonomic nervous reactivity during the HRVBF session.

\section{Discussion}

The selection of short-term training with biofeedback is required to restore autonomic nervous system balance in adolescents during the intense training process, when there is not enough time to implement a long-term training in a course with biofeedback procedures. Our previous studies involving adolescents slightly younger than the examined group (14-15 years of age) showed a more pronounced effectiveness of the short-term HRV-BF training (3min)after performing a physical load of a speed-strength nature than the control group that did not use this training. ${ }^{(13)}$ Consequently, in healthy adolescents without pathology of the cardiovascular system, baroreflex mechanisms should be sufficiently formed to implement selfregulation in the management of the cardiorespiratory system's own functions, even for such a short time period. However, the problems of the psycho-emotional sphere and behaviors in adolescents with Internet overuse were frequently associated with a reduction in overall HRV, with disturbances in vagal regulation of the heart rhythm. ${ }^{(4,5)}$
The results of the present study showed that the baseline HRV indicators in adolescents with a minimal risk and those with a pronounced risk of Internet-dependent behavior were identical, without signs of a pronounced decrease in overall HRV. However, the implementation of a short-term HRV$\mathrm{BF}$ session in individuals with a pronounced risk of IA was obviously difficult. It can be assumed that against the background of neurobiological disorders that cause the risk of dysthymia, affective and social-anxiety disorders, and depression in Internet-dependent adolescents, ${ }^{(1)}$ disturbances in the sensations of signals from their own body also develops and, therefore, the effectiveness of biological feedback decreases. Nevertheless, it should be noted that a similar low HRV-BF efficiency was not found in individuals with high CIAS score, but with an initially high TP of HRV (i.e. in persons with pronounced vagal reserves of cardiac activity). The leading role of the CIAS Wit-score for Internet overuse in reducing the effectiveness of HRV-BF requires further study of adolescents with a wider age range. Thus, even the presence of a moderately pronounced risk of developing Internetdependent behavior at the stage when age-related autonomic regulation of cardiac activity is formed in adolescents may be accompanied by a decrease in the ability to self-regulate. The low effectiveness of HRV-BF shows the difficulty monitoring bodily functions in individuals with predominantly withdrawal symptoms (i.e. with a deterioration in well-being when access to Internet resources is impossible). It is assumed that the longterm HRV-BF training can provide the optimization of corticovisceral connections and reduce the risk of psychosomatic disorders in persons with Internet-dependent behavior.

\section{Competing Interests}

The authors declare that they have no competing interests.

\section{Sources of Funding}

The reported study was funded by the FCIARctic according to the research project No AAAA-A19-119120990083-9 and RFBR grant No 20-013-00060.

\section{References}

1. Cerniglia L, Zoratto F, Cimino S, Laviola G, Ammanti $\mathrm{M}$, Adriani W. Internet Addiction in adolescence: Neurobiological, psychosocial and clinical issues. Neurosci Biobehav Rev. 2017;76(Pt A):174-184. doi: 10.1016/j. neubiorev.2016.12.024.

2. Chen S, Weng L, Su Y, Wu H, Yang P. Development of a Chinese Internet addiction scale and its psychometric study. Chinese Journal of Psychology. 2003.45:279-294.

3. Kwok-Kei Mak, Ching-Man Lai, Chih-Hung Ko, Chien Chou, Dong-Il Kim, Hiroko Watanabe, Roger C M Ho. Psychometric properties of the revised Chen Internet Addiction Scale (CIAS-R) in Chinese adolescents. J Abnorm Child Psychol. 2014;42(7):1237-45. doi: 10.1007/s10802-014-9851-3.

4. Kim N, Hughes TL, Park CG, Quinn L, Kong ID. Altered Autonomic Functions and Distressed Personality Traits in Male 
Adolescents with Internet Gaming Addiction. Cyberpsychol Behav Soc Netw. 2016;19(11):667-673. doi:10.1089/ cyber.2016.0282..

5. Moretta T, Buodo G. Autonomic stress reactivity and craving in individuals with problematic Internet use. PLoS One. 2018;13(1):e0190951. Published 2018 Jan 16. doi:10.1371/ journal.pone.0190951

6. Lehrer PM, Gevirtz R. Heart rate variability biofeedback: how and why does it work? Front Psychol. 2014;5:756. doi: 10.3389/fpsyg.2014.00756.

7. Poskotinova LV, Demin DB, Krivonogova EV. Short-term HRV Biofeedback: Perspectives in Environmental Physiology and Medicine. International Journal of Biomedicine. 2017;7(1):24-27. doi: 10.21103/Article7(1)_RA3

8. Order № 514n Ministry Of Health Russia [ «O Poryadke provedeniya profilakticheskikh meditsinskikh osmotrov nesovershennoletnikh»], dated 2017 August 10. [Article in Russian]. [cited 2020 April 20]. Available from: http://base. garant.ru/71748018.

9. WHO. Growth reference data for 5-19. Available from: https://www.who.int/growthref/en/.

10. Malygin VL, Feklysov KA, Iskandirova AB, Antonenko AA. [Methodological approaches to the early detection of
Internet-dependent behavior]. [Article in Russian ]. [Electronic source]. Medical Psychology in Russia: an electronic scientific journal. 2011;6. Available from: http://medpsy.ru/mprj/ archiv_global/2011_6_11/nomer/nomer03.php.

11. Ko CH, Yen JYY, Yen CF, Chen CC, Yen CN, Chen SH. Screening for Internet addiction: an empirical study on cutoff points for the Chen Internet Addiction Scale. Kaohsiung J Med Sci. 2005;21(12):545-551. doi:10.1016/S1607551X(09)70206-2.

12. Patent RUS № 2317771. Poskotinova LV, Semenov YuN. Method for correcting vegetative misbalance states with Varicard complex for processing cardiointervalograms and analyzing cardiac rhythm variability, operating under computer software program with biofeedback. [Abstract of invention in Russian]. Available from: https://patentimages.storage. googleapis.com/2a/b4/c7/68fcfa35cce6e1/RU2317771C2.pdf 13. Poskotinova LV, Krivonogova OV, Zaborsky OS. Indicators of a Cardiovascular System at 14-15 Years Old Boys at Short-term Biofeedback Training for Controlling of General Heart Rate Variability After Speed and Power Training: Experimental Controlled Study. Current Pediatrics. 2019;18(3):167-174. doi:10.15690/vsp.v18i3.2033. [Article in Russian]. 